\title{
Producción de fracciones antioxidantes de sangre bovina
}

Omar Figueroa', Karen Ospino², Emil Mejia ${ }^{3}$, Sandy Peñaloza ${ }^{4}$, Jesús Morales ${ }^{5}$

\section{Resumen}

En este trabajo se analizó el efecto del grado de hidrólisis (GH) de hidrolizados enzimáticos de fracciones de sangre bovina (plasma y fracción globular) con alcalasa 2,4 litros sobre la actividad antioxidante de fracciones peptídicas. A las condiciones óptimas se produjeron hidrolizados en tres tiempos de hidrólisis para evaluar la capacidad antioxidante, con los métodos ORAC, ABTS y FRAP, alcanzando, en general, mayor capacidad antioxidante en el tiempo de dos horas, salvo para el caso de la capacidad en los agentes antioxidantes de la fracción globular medidos con la técnica ABTS, en la que resulta suficiente hidrolizar 30 min y obtener hidrolizados intermedios para favorecer la mayor capacidad antioxidante, siendo esta estadísticamente igual a las fracciones con alto GH.

Palabras clave: antioxidantes, hidrolizados enzimáticos, péptidos bioactivos, sangre bovina.

1 M. Sc. en Ciencias Farmacéuticas y Alimentarias de la Universidad de Antioquia, Medellín. Correo: omar.figueroa@udea.edu.co

2 M. Sc. en Ingeniería de la Universidad Popular del Cesar, Valledupar. 3 Ingeniera agroindustrial de la Universidad Popular del Cesar, Valledupar. 4 Ingeniera agroindustrial de la Universidad Popular del Cesar, Valledupar. 5 Ingeniero agroindustrial de la Universidad Popular del Cesar, Valledupar. 


\section{Introducción}

El estrés oxidativo es el resultado de un exceso de radicales libres de oxígeno en el cuerpo humano, es por esto que los antioxidantes, entendiendo estos como "cualquier sustancia que, en presencia de un sustrato oxidable, retrasa o inhibe la oxidación del mismo" (Korhonen y Pihlanto, 2006), juegan un papel muy importante en la prevención de dichas enfermedades.

Existe una relación entre la ingesta de compuestos antioxidantes y las enfermedades. "La actividad antioxidante de péptidos bioactivos en particular, pueden ser atribuida a la eliminación de radicales, la inhibición de la peroxidación lipídica y las propiedades de quelación de iones metálicos de los péptidos" (Sarmadi e Ismail, 2010).

Los antioxidantes sintéticos convencionales (BHA, BHT y n-propilo galato) muestran una fuerte actividad contra varios sistemas oxidantes, pero presentan estricta regulación en su uso por su relación con riesgos potenciales a la salud. En tal medida, la tendencia actual es utilizar productos naturales antioxidantes cuya actividad se lleve a cabo no solo en los alimentos envasados, sino tam- bién una vez el alimento ha sido ingerido. (Sabeena Farvin et al., 2014)

A pesar de que la sangre bovina es un subproducto abundante caracterizado por ser una fuente proteica de alta calidad, no se le ha dado el debido interés, considerando su enorme potencial de aplicación y utilización.

Debido al alto valor nutricional de la sangre, su fácil obtención y la abundancia con que se genera, se hace necesario el desarrollo de investigaciones aplicadas que motiven la valoración y diversifiquen las estrategias de aprovechamientos de residuos industriales como herramientas clave en la generación de valor agregado a productos de bajo valor económico. Un enfoque actual de gran interés lo representa la búsqueda de péptidos bioactivos, en especial los que poseen propiedades antioxidantes (Liu et al., 2010).

Estas razones, unidas a la necesidad de desarrollar nuevos productos con características funcionales definidas, ha conducido al estudio de procesos de hidrólisis enzimática, utilizando como sustrato fuentes proteicas alternativas. El objeto del trabajo presentado es evaluar el potencial de aplicación como antioxidante de la sangre bovina en sus fracciones (plasma y fracción globular) 
y sus hidrolizados enzimáticos, así como analizar el papel de variables significativas como el $\mathrm{pH}$ en el rendimiento de las reacciones que definen la formación de estos compuestos de interés.

\section{Materiales y métodos}

\section{Enzima, sustrato e hidrolizados enzimáticos}

El sustrato utilizado fue sangre de bovino higienizada y suministrada por un proveedor comercial de la ciudad de Medellín, Colombia. La sangre fue centrifugada empleando una centrifugadora marca Boeco referencia: 1406-12 (8500 rpm, $4{ }^{\circ} \mathrm{C}$ por $15 \mathrm{~min}$ ). Posteriormente, la fracción globular y plasmática se almacenó a $-20{ }^{\circ} \mathrm{C}$ para su posterior hidrólisis. Para la hidrólisis se usó Alcalase $\AA$ 2,4 litros grado alimenticio (Novozymes, Dinamarca), cuyo componente principal es subtilisina A (Subtilisina Carlsberg).

En la reacción se emplearon reactores de vidrio de $0,5 \mathrm{~L}$ conectados a un regulador termostático y control de $\mathrm{pH}$ a través de un titulador automático Titrando 842 (Metrohm, Suiza). Las condiciones de hidrólisis fueron ajustadas de acuerdo con los experimentos planeados y la reacción se inicia con la adición de la cantidad de enzima justa.
Reacción de hidrólisis enzimática

La reacción fue monitoreada para la determinación del gh, expresado como la relación entre el número de enlaces peptídicos cortados en la hidrólisis (h) y el número de enlaces peptídicos totales en la proteína nativa por unidad de peso (ht). Para este caso, se empleó un ht de 8,3 Eqv/ Kg (Márquez y Vázquez, 1999). El método empleado para la determinación del GH es el de valoración del protón o método del $\mathrm{pH}$-stat ecuaciones (1-3). (Adler-Nissen, 1986)

$$
\begin{aligned}
& G H=\frac{B N_{B}}{M_{p}} \frac{1}{\alpha} \frac{1}{h_{t}} 10 \\
& \alpha=\frac{10^{p H-p K}}{1+10^{p H-p K}} \\
& p k=7,8+\frac{298-T}{298 \times T} 2400
\end{aligned}
$$

Donde B es el Volumen consumido de base en litros, NB = Normalidad de la base (Eqv/L), Mp es Masa de la proteína en $\mathrm{Kg}$ y $\alpha$ es el grado de disociación de los grupos $\alpha$-NH2 liberados en la reacción, el cual depende del pK, que a su vez está asociado con la temperatura. (Valencia et al., 2015) 


\section{Métodos analíticos}

Para la caracterización de los sustratos proteicos se emplearon técnicas oficiales de análisis. La determinación de cenizas se hizo calcinando la muestra a $550^{\circ} \mathrm{C}$ en una mufla modelo D8 (Terrígeno, Colombia) por un periodo de 5 horas (AOAC 14.006). El contenido proteico se llevó a cabo por el método de determinación del nitrógeno total microkjendahl (AOAC 991.20) en un equipo dk 6 (Heating Digester, usa). La determinación de grasa se hizo por el método de Gerber (AOAC 2000.18) (AOAC Official Methods of Analysis n.d).

Para la medición de la capacidad antioxidante se emplearon los métodos de determinación directa ABTS basados en la decoloración del radical (ácido 2,2' azinobis-3- etilbenzotiazolina-6- sulfónico) provocado por la interacción con moléculas donantes de electrones; se basó en la metodología descrita por Re, et al (1999). Además, se usaron técnicas indirectas: orac, la cual emplea un mecanismo de donación de un átomo de hidrógeno y se hizo siguiendo la metodología descrita por Ou et al (2001); y frap, que usa como principio la reducción en un medio ácido el hierro férrico $(\mathrm{Fe}+3)$ hasta la forma ferrosa $(\mathrm{Fe}+2)$; se siguió la metodología ajustada de Pulido, et al. (2000).
Para los tres métodos se establecieron curvas de calibración con diferentes concentraciones del antioxidante estándar Trolox (análogo hidrofílico del alfa tocoferol). Todos los reactivos usados para la medición de capacidades antioxidantes fueron de grado analítico.

\section{Datos experimentales}

Las muestras de plasma bovino (pb) y fracción globular (fgb) de sangre bovina se tomaron a condiciones óptimas de Temperatura, enzima y sustrato según estudios anteriores del grupo. Hidrólisis enzimáticas a distintos valores de $\mathrm{pH}$ muestran el efecto del mismo sobre el gh como medida de rendimiento de la reacción. Las curvas y los análisis de antioxidantes se hicieron por triplicado.

\section{Resultados y discusión}

En la tabla 1 se muestra el resultado para la caracterización bromatológica del sustrato. Estos resultados son coherentes con los declarados en numerosas fuentes bibliográficas.

Son de gran interés los resultados del porcentaje de proteínas encontrado, pues permite corroborar que se trata de material con alto potencial de utilización para hidrólisis enzimática. 
Desde el punto de vista de la nutrición, las proteínas y péptidos procedentes de alimentos están siendo empleados con el fin de mejorar algunas funciones biológicas o de tratar de prevenir o reducir el riesgo de enfermedad, pues se ha establecido, que algunos péptidos obtenidos por hidrólisis de proteínas, son capaces de ejercer efectos biológicos específicos. (Liu et al., 2010)

Tabla 1. Caracterización de plasma entero (PB) y fracción globular (FGB) bovino

\begin{tabular}{lll}
\hline Componente & $\mathrm{pb}$ & $\mathrm{fgb}$ \\
\hline Porcentaje de proteína $(\mathrm{p} / \mathrm{v})$ & 8,3 & 39 \\
\hline $\mathrm{pH}$ & 6,7 & 7,4 \\
\hline Densidad $(\mathrm{g} / \mathrm{mL})$ & 1,061 & 1,087 \\
\hline Porcentaje de grasa $(\mathrm{p} / \mathrm{p})$ & 0,03 & 0,21 \\
\hline Porcentaje de cenizas (p/p) & 0,44 & \\
\hline Rendimiento centrifugación & $60 \%$ & $40 \%$ \\
\hline
\end{tabular}

En la tabla 2 se muestran las actividades antioxidantes reportadas por varios métodos de PB, FGB y sus hidrolizados para distintos tiempos de reacción hasta dos horas máxima. Para este estudio se analizó el comportamiento de los valores de antioxidantes para hidrolizados en los tramos iniciales, medios y final de la reacción. Esto concuerda con la denominación de bajo, medio y alto grado de hidrólisis relativo, en cada caso.

A través de la hidrólisis con Alcasa 2,4 L se favorece la capacidad antioxidante de la fracción globular de sangre bovina. Como se ha evidenciado en numerosos trabajos el tiempo de hidrólisis aumenta con el tiempo y este a su vez la capacidad antioxidante, esta tendencia se observó en los resultados de Bah et al. (2015). La capacidad antioxidante de hidrolizados enzimáticos depende, en gran medida, del peso molecular y de la estructura y secuencia de la cadena de aminoácidos de la estructura peptídica resultante (Chalamaiah et al., 2012). En muchos casos el GH resulta ser una herramienta indirecta para describir la distribución del peso molecular de los hidrolizados, en el sentido que una prolongada hidrólisis redunda casi siempre en grados de hidrólisis altos y, por tanto, tamaños peptídicos mucho más pequeños (Morales y Medina et al., 2017). 
Tabla 2. Resultados de pruebas de capacidad antioxidantes de sustratos e hidrolizados enzimáticos de fracción globular sin hidrolizar (FGSH) y plasma bovino sin hidrolizar (PBSH) y sus respectivos hidrolizados con bajo, medio y alto grado de hidrólisis. Para Hidrolizados de fracción globular: $\mathrm{T}=55^{\circ} \mathrm{C}, \mathrm{pH}=9$ y de plasma $\mathrm{T}=61^{\circ} \mathrm{C}, \mathrm{pH}=9$

\begin{tabular}{|l|l|l|l|}
\hline Muestra & orac & frap & abts+ \\
\hline FG e Hidrolizados & $\begin{array}{l}234,1 \\
\pm 21\end{array}$ & $45,2 \pm 2,5$ & $608,9 \pm 4,1$ \\
\hline fgsh & $\begin{array}{l}461,2 \\
\pm 37,7\end{array}$ & $54,8 \pm 2,2$ & $747,5 \pm 68,5$ \\
\hline Hbajo & $\begin{array}{l}464,2 \\
\pm 14,0\end{array}$ & $57,4 \pm 1,8$ & $725,6 \pm 56,0$ \\
\hline Hmedio & $\begin{array}{l}513,7 \\
\pm 8,2\end{array}$ & $65,3 \pm 5,8$ & $748,3 \pm 71,3$ \\
\hline Halto & - & $18,5 \pm 2,5$ & $174 \pm 6,7$ \\
\hline pb e hidrolizados & - & $68,3 \pm 3,2$ & $783,4 \pm 7,6$ \\
\hline pbsh & - & $91,6 \pm 4,2$ & $1032,6 \pm 9,0$ \\
\hline Hbajo & - & $125,7 \pm 4,0$ & $1413,3 \pm 20,3$ \\
\hline Hmedio & & & \\
\hline Halto & & & \\
\hline
\end{tabular}

En el análisis de antioxidante de la fracción globular e hidrolizados, los resultados por los métodos de ORAC y FRAP, al aplicar la prueba de múltiples rangos de Duncan, se agrupan en dos columnas, en las que el gh alto difiere significativamente $(p<0,05)$. En el análisis de abts se agrupan en una columna, no difiriendo en ninguno de los hidrolizados analizados $(p<0,05)$. Esto implica que para obtener la mayor capacidad de reducción de radicales libres de oxígeno y Fe se debe efectuar a un tiempo de hidrólisis de dos horas para llegar a un gh bajo las condiciones óptimas, mientras que para obtener la máxima capacidad de los agentes antioxidantes de la hemoglobina bovina para atacar el catión radical ABTS+ basta con ejecutar la hidrólisis enzimática a 30 minutos o cualquier otro tiempo estudiado.

En tanto, los resultados para las muestras de plasma y sus hidrolizados registran valores satisfactorios en la medida en que se ha comprobado la capacidad antioxidante de hidrolizados de plasma bovino y que, efectivamente, 
esta actividad se potencia significativamente $(\mathrm{p}<0,05)$ con la hidrólisis (HyunWoo et al., 2015).

Según Cumby et al. (2008), este fuerte poder reductor se puede atribuir a la mayor disponibilidad de iones de hidrógeno (protones y electrones) debido a las divisiones de péptidos. Se sabe que la Alcalasa es una endopeptidasa que actúa sobre los enlaces peptídicos en el interior de la cadena polipeptídica, por lo que produce principalmente oligopéptidos y polipéptidos pequeños y medianos, algunos de los cuales son antioxidantes (Cumby et al., 2008).

Los resultados logrados en el presente trabajo indican, que la hidrólisis enzimática podría mejorar significativamente el potencial antioxidante de los hidrolizados a través de la extensión del tiempo de hidrólisis, puesto que fracciones de proteínas con peso molecular grande son paulatinamente degradadas a fracciones de peso molecular relativamente pequeñas. En esta medida, uno de los mecanismos que conduce al aumento de la actividad puede estar asociado con la exposición de aminoácidos específicos en las cadenas peptídicas resultantes (Rajapakse et al., 2005).

Por otra parte, la capacidad de reducción del ion $\mathrm{Fe}+3$ fue muy superior a las reportadas por Liu et al. en plasma porcino, por ejemplo, lo cual puede relacionarse con el GH alcanzado, pues se ha comprobado que este es proporcional a la capacidad antioxidante hasta cierto límite, cuando los péptidos son hidrolizados hasta sus unidades fundamentales (Liu et al., 2010).

En general, la captación de radicales libres de los hidrolizados de proteína del plasma se puede explicar a través de varios mecanismos que incluyen la capacidad de donar hidrógeno, estabilizar radicales, secuestrar iones metálicos prooxidativos y, probablemente, formar una barrera física alrededor de las gotas de grasa usando aminoácido especial (Hyun-Woo et al., 2015).

La tabla 3 muestra los resultados de gh para distintos valores de $\mathrm{pH}$ evaluados.

Considerando la naturaleza bioquímica de la reacción, cambios importantes se registran en el rendimiento de la reacción cuando se presentan leves incrementos en el $\mathrm{pH}$ de la misma, hasta ciertos niveles indicados, esto contrasta con las disminuciones observadas en la velocidad de ruptura de enlaces peptídicos cuando los valores de $\mathrm{pH}$ son inferiores, Mientras que valores intermedios de 
pH registran mejores resultados en términos de rendimiento en reacciones de este tipo. Estos fenómenos son comunes puesto que es sabido que cambios en el $\mathrm{pH}$, pueden influenciar la disociación de grupos activos de la enzima, afectando la dinámica de asociación de esta con el sustrato. (Liu et al., 2010)

\section{Tabla 3. Grado de hidrólisis final de hidrolizados de FG y PB a distintos valores de pH}

\begin{tabular}{lllll}
\hline Fuente & SO $(\mathrm{m} / \mathrm{v})$ & $\begin{array}{l}\mathrm{EO} / \mathrm{SO} \\
(\mathrm{m} / \mathrm{m})\end{array}$ & $\mathrm{pH}$ & gh (\% 2 horas) \\
FG & 10,5 & 8 & 7,3 & 22,7 \\
& & & 9 & 30,3 \\
& & & 10,6 & 22,5 \\
$\mathrm{pb}$ & 6 & 7,5 & 7,4 & 18,7 \\
& & & 8,2 & 21 \\
& & & 9 & 21,5 \\
\hline
\end{tabular}

\section{Conclusión}

El pH juega un papel importante en el rendimiento de la reacción de hidrólisis enzimática de proteínas, pues interviene en la disociación de grupos activos de la enzima, por tanto, es de vital importancia ajustar los valores de $\mathrm{pH}$ adecuados para el trabajo de la enzima con cada sustrato. En general, la capacidad antioxidante de los hidrolizados mejora en relación con la de los sustratos nativos y se potencia en la medida en que aumenta el gh.

\section{Referencias}

AOAC 14.006, 991.20, 2000.18 (2007). Association of Analytical Communities (International). Official Methods of Analysis.

Bah, C., Bekhit, A., Carne, A., McConnell, M. (2015). Production of bioactive peptide hydrolysates from deer, sheep and pig plasma using plant and fungal protease preparations. Food Chemistry, 176, 54-63.

Chalamaiah, M. (2012). Dinesh Kumar, B., Hemalatha, R. y Jyothirmayi, T. Fish. Protein hydrolysates: Proximate composition, amino acid composition, antioxidant activities and applications: A review. Food Chemistry, 135, 3020-3038.

Cumby, N., Zhong, Y., Naczk, M. y Shahidi, F. (2008). Antioxidant activity and water-holding capacity of canola protein hydrolysates. Food Chemistry, 109, 144-148. 
Hyun-Woo, S., Eun-Young, J., Gwang-Woong, G., Gap-Don, K. Seon-Tea, J. y Han-Sul, Y. (2015). Optimization of hydrolysis conditions for bovine plasma protein using response surface methodology. Food Chem, 185, 106-111.

Liu, Q., Kong, B., Xiong, Y.L. y Xia, X (2010). Antioxidant activity and functional properties of porcine plasma protein hydrolysate as influenced by the degree of hydrolysis. Food Chemistry, 118, 403-410.

Korhonen, H. y Pihlanto, A. (2007). Bioactive peptides: Production and functionality. Int. Dairy J., 4th NIZO Dairy Conference. Prospects for Health, Well-being and Safety4th NIZO Dairy Conference. Prospects for Health, Well-being and Safety, 16, 945 960.

Márquez, M. C. y Vázquez, M.A (1999). Modeling of enzymatic protein hydrolysis. Process Biochemistry, 35, 111-117.

Morales-Medina, R., Pérez-Gálvez, R., Guadix, A. y Guadix, E.M. (2017). Multiobjective optimization of the antioxidant activities of horse mackerel hydrolysates produced with protease mixture. Process Biochem., 52, 149-158.

Ou, B., Hampsche-Woodill, M. y Prior, R. (2001). Development and validation of an improved oxygen radical absorbance capacity assay using fluorescein as the fluorescent probe. Journal of Agricultural and Food Chemistry, 49(10), 4619-4626.
Pulido, R., Bravo, L. y Saura-Calixto, F. (2000). Antioxidant activity of dietary polyphenols as determined by a modified ferric reducing/antioxidant power assay. Journal of Agricultural and Food Chemistry, 48(8), 3396-3402.

Rajapakse, J., Mendis, E., Jung, W. K., Je, J. Y., y Kim, S. K. (2005). Purification of a radical scavenging peptide from fermented mussel sauce and its antioxidant properties. Food Research International, 38, 175-182.

Re, R., Pellegrini, N., Proteggente, A., Pannala, A., Yang, M. y Rice-Evans, C (1999). Antioxidant activity applying an improved ABTS radical cation decolorization assay. Free Radical Biology y Medicine, 26(9), 1231-1237.

Sarmadi, B.H. e Ismail, A (2010). Antioxidative peptides from food proteins: A review. Peptides 31, 1949-1956.

Sabeena Farvin, K. H., Andersen, L. L., Nielsen, H.H., Jacobsen, C., Jakobsen, G., Johansson, I. y Jessen, F. (2014). Antioxidant activity of Cod (Gadus morhua) protein hydrolysates: In vitro assays and evaluation in 5\% fish oil-in-water emulsion. Food Chem., 149, 326-334. doi:10.1016/j.foodchem.2013.03.075

Valencia, P., Espinoza, K., Ceballos, A., Pinto, M. y Almonacid, S. (2015). Novel modeling methodology for the characterization of enzymatic hydrolysis of proteins. Process Biochem, 50, 589-597. 